\title{
A comprehensive study of Employee Engagement: Contemplating 7-D model in view of NIFTY 50
} companies

\author{
Avik Ghosh, Suman Sourav
}

CMA, The Institute of Cost And Management Accountants of India, Sudder Street, Kolkata, India

E-mail: agsresearch@yahoo.com

MBA, Indian Institute of Management, Prabandh Shikar, Indore, India

E-mail: p13sumans@iimidr.ac.in

\begin{abstract}
The study has been initiated to unfold the conceptual reality of a commonly used terminology in organization behaviour study-employee engagement. The engagement of employees towards an organization is determined by their affective, cognitive and behavioural attributes which are in turn linked with various internal and external factors. These factors are identified and presented in various models with some specific focus area. Employee engagement index, the measuring indicator, is a reflection of multiple self-determining factors. This study unveiled the factors while analysing the annual reports for FY 2018-19 of NIFTY 50 companies. The key focus areas have been identified and an all-encompassing 7-Dimensional model has been proposed to determine the objectiveoriented factors to prepare relevant questionnaire for ascertaining Employee Engagement Index.
\end{abstract}

Keywords- Employee Engagement, Engagement Models, Engagement study of NIFTY 50 companies, Engagement Drivers.

\section{INTRODUCTION}

In Human Resource Management, the key resource factor is 'Human' where the organization is driven by the wellbeing and mental health of them. They are the employees of the organization. In this context, the mental health of the employees is driven by various internal and external factors or driving forces. The most talked about are motivation level, behavioral attributes, organizational bonding, work culture, leadership skills etc. This paper will unveil one such factor that drives the mental framework of the employees and subsequently the organizational outcome in terms of profit, higher stock price, achievement of target. This is employee engagement. The broadly used term is sometimes loosely meant and the actual essence is also diluted very often. This indicator not only highlights the mental framework of the employees but also reflects the organizational potential to utilize the employees towards achieving its vision.

Study by ADP Research Institute's (ADPRI) et al(2019) on employee engagement titled new global study of Engagement have found that $84 \%$ of employee are merely 'coming to work' and are not contributing entirely to their organizations. KPI metrics by Survey Sparrow et al (2019) have shown that
Enterprise with highly engaged employees have 41 percent lower absentee rates and 59 percent less turnover. Companies with an engaged workforce have 5 times higher shareholder returns and highly engaged employees are 21 percent more productive.

Employee Engagement has been well defined by David Macleod as "This is about how we create the conditions in which employees offer more of their capability and potential". This essentially creates a solid link between the ability and skill sets of the employees with the objectives and vision of the organization. Various models have been developed to ascertain the outcome of the employee engagement by measuring employee engagement index (EEI). The calculation of employee engagement index is usually based on multiple parameters and specific weightages to each of the parameters.

\section{PREVIOUS RESEARCH}

Kahn et al (1990) have defined employee engagement as "the harnessing of organization members' selves to their work roles. In Employee engagement, people employ and express themselves physically, cognitively, and emotionally during 
role performances". The second approach to the concept of engagement was in research on burnout. Maslach and Leiter et al. (1997) and Maslach et al. (2001) conceptualized engagement as opposite or the positive antithesis to the three burnout dimensions: exhaustion, cynicism, and sense of inefficacy. Schaufeli et al. (2002) provided a third approach for employee engagement, asserting that job engagement and burnout were independent states of mind and inversely related to each other.Wellins and Concelman et al (2005) suggested that engagement is an amalgamation of commitment, loyalty, productivity and ownership. Wellins and Concelman (2005) further said that engagement is the illusive force that motivates employees to higher (or lower) levels of performance.

According to Robinson et al (2006), employee engagement can be achieved through the creation of an organizational environment where positive emotions such as involvement and pride are encouraged, resulting in improved organizational performance, lower employee turnover and better health. Robertson-Smith and Markwick (2009) threw light on what engagement is and revealed that it is an important yet complex challenge, and there remains a great deal of scope for discussing the various approaches. Simpson et al (2009) discussed the current state of knowledge on engagement at work through a review of the literature. This review highlighted the four lines of engagement research and focused on the determinants and consequences of engagement at work. Susi \&Jawaharrani et al (2011) examined some of the literature on Employee engagement, explored work-place culture \& work-life balance policies \& practices followed in industries to promote employee engagement in their organizations to increase their employee productivity and retention.

Agarwal et al (2015) had attempted to test the level of engagement among employees and paper explain about the predictors of employee engagement in public sector unit in Indian context. Agarwal \& Ojha et al (2016) had found the employee engagement considering the Generation Y specific traits, needs and expectations. A focus on the study was given in understanding as how Generation $\mathrm{Y}$ employees behave and what motivates them and how it is different from generation $\mathrm{X}$ employees.

\section{INITIAL THEORY FRAMEWORK AND RESEARCH METHODOLOGY}

The purpose of the research was to assess and analyze the existing models related with employee engagement and to establish an all-encompassing model to reflect the relevant aspects in a manner that suits the engagement factor. The Indian companies which are part of NIFTY 50 Index were analyzed based on their Annual Report to assess the focus and mention of Employee Engagement. The employee engagement is usually measured considering weighted average of various relevant indicators / factors. This questionnaire is usually prepared with a focused methodology (Figure: 1) and some standard practices followed either globally (Figure: 2) or in alignment with company vision and mission statements.

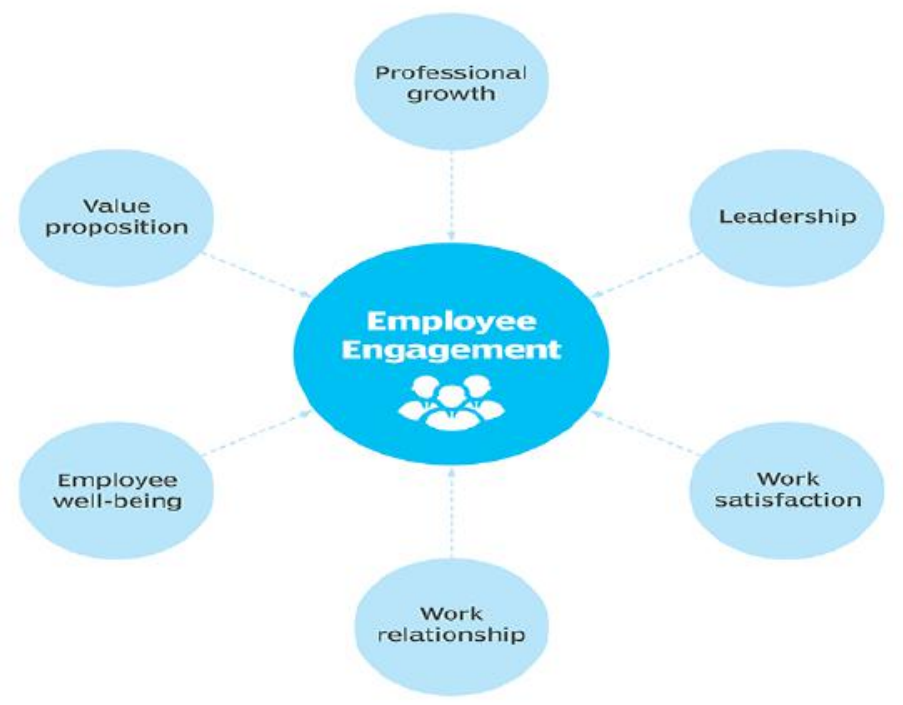

Fig.1: Deciding factors 


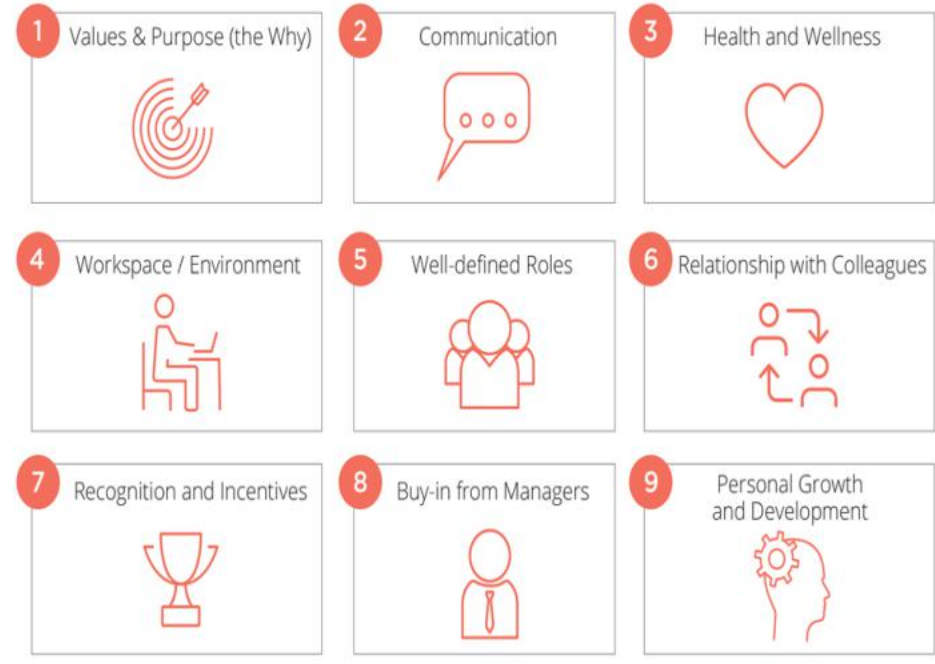

Fig.2: Globally accepted Questionnaire parameters

We have pointed out such parameters in the global context and zeroed in on India's perspective with the listed companies with considerable market capitalization. We have studied Annual Reports for FY 2018-19 of all the companies and captured the number of times they have used employee engagement term in it reflecting their willingness to consider this as a defining factor. Once the study is performed, the outcome was analyzed based on multiple defining questions which were expected to be answered while fetching the employee engagement. All these questions are not answered in any of the existing models resulting in partial veracity of the models. We proposed the pertinent questions that act as inputs to the engagement black box and the output, the employee engagement index, consists of most of the deciding indicators.

\section{PRESENTATION AND EXPLANATION OF PREVAILING MODELS AND DATA}

\subsection{Employee engagement models:}

All these models are relevant and explicitly contain in-depth study of the engagement factor. However, most of them talk about one or two dimensions of the input factors namely need, motivation, leadership, performance, benefits etc. These factors are oriented either towards internal factors or inclined towards external factors. When Maslow's Need Hierarchy is matched with engagement, the outcome tends to correlate the psychological health with engagement factors (Table: 1).
Table: 1: Needs Vs Engagement

\begin{tabular}{|l|l|}
\hline Motivators / Needs & State of Engagement \\
\hline Survival & Disengaged \\
\hline Security & Not engaged \\
\hline Belonging & Almost engaged \\
\hline Esteem & Engaged \\
\hline Self Actualization & Highly engaged \\
\hline
\end{tabular}

Gallup's Engagement Hierarchy focuses on basic needs, management support, team work and growth factors where the questionnaire is prepared considering the broad elements namely 'What do I give?', 'What do I get', 'Do I belong?' and 'How can we grow?' All these questions and its potential answers are weighted with a predetermined weightage and the employee engagement index is calculated

Aon Hewitt's Model of Engagement is exhaustive in terms of explaining engagement factors ranging from need, motivation to work culture and leadership. The drivers ensure engagement outcomes and the employees have been classifies as Say (actively engaged in propagating best practices of the organization and actively engaged), Stay (Inclines towards organizational goals) and strive (feeling difficulty to achieve targets) (Table: 2). The employee outcomes lead to business outcomes in all relevant parameters like operational, financial, customer health and human resource health. 
Table: 2: Engagement Drivers, Outcomes vis-à-vis Business Outcomes

\begin{tabular}{|l|l|l|l|}
\hline Engagement Drivers & Engagement Outcomes & Business Outcomes \\
\hline Foundation & Differentiators & Say & Talent Retention \\
\hline The work & Brand & Stay & Operational Improvement \\
\hline The basics & Leadership & Strive & Customer Satisfaction \\
\hline Company Practices & Performance & & Financial well being \\
\hline
\end{tabular}

Towers Watson's Engagement Model is having emotional bias where 3 E's of engagement are specified as Engaged, Enabled and Energized. These 3 E's are derived from rational, emotional and motivational factors which are called Think, Feel and Act factors respectively. He also emphasized the importance of leadership qualities in improving the engagement factors. He pointed out leadership factors as Inspire, Envision, Adapt and Transform which impact the employee engagement at first place and subsequently business outcome in the longer run.

Both IES Survey in 2003 and Robinson Model of employee engagement focused on the identification of importance of factors to contribute to employee engagement. The hygiene factors were mostly rated as less important than the motivation factors in determining the employee engagement. Schmidt Model (Figure: 3) emphasizes more on the recruitment of the right workforce and maintains strong balance in work place to ensure employee engagement. Survival and security needs, mostly the hygiene factors, were given utmost priorities. Penna's Model (2007) (Figure: 4) illustrated a hierarchy of factors contributing to employee engagement. It started with basic working conditions followed by learning \&developing,careeradvancement, good leadership, trust and respect and a better meaning to work.

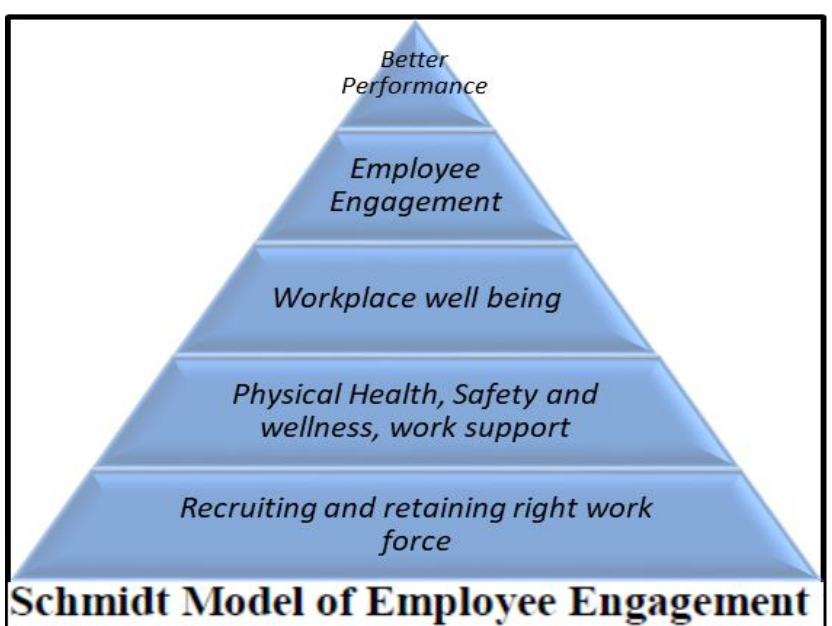

Fig: 3: Schmidt Model

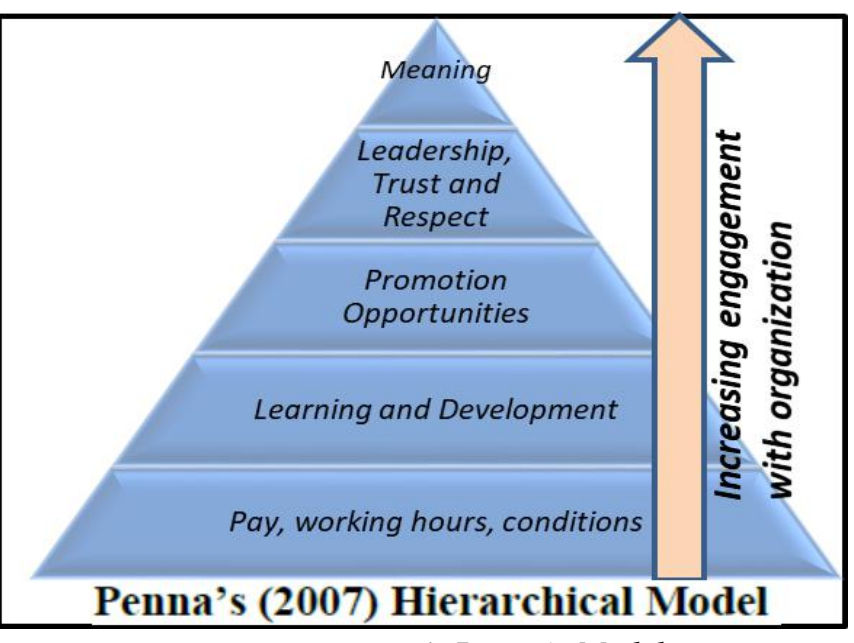

Fig: 4: Penna's Model

Zinger suggested ten building blocks (Figure: 5) which are key to create, maintain and increase employee engagement. It is a four-layered model that starts with basic blocks of

hygiene needs and end up at the apex level with better organizational performance. 


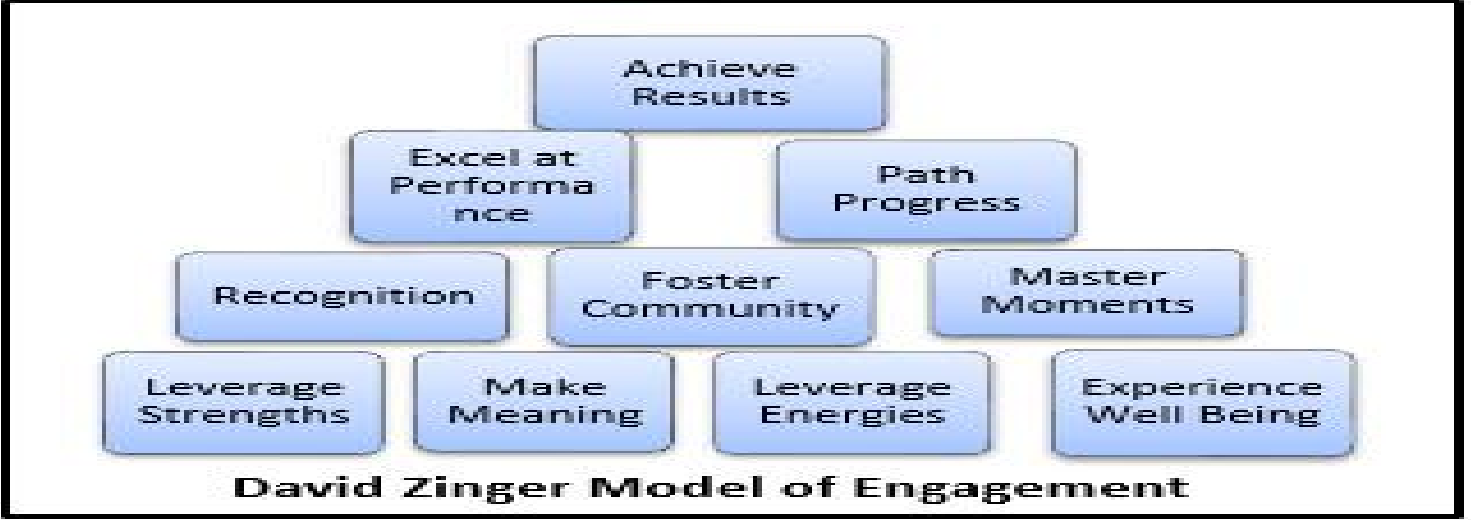

Fig: 5: David Zinger Model

Once all these established models are analyzed from organizational point of view and its effectiveness in a specific organizational environment are evaluated, it is found that all these models are generic models and based on various theories pertaining to organizational behavior.

\subsection{Data analysis for NIFTY 50 Companies from Annual Report 2018-19}

Table: 3: Data Analysis for NIFTY 50 from 2018-19 Annual Report

\begin{tabular}{|l|l|l|}
\hline \multicolumn{1}{|c|}{ Company Name } & $\begin{array}{c}\text { No. of times } \\
\text { Employee } \\
\text { Engagement } \\
\text { Word Used }\end{array}$ & Employee Engagement Platform \\
\hline Adani Ports and Special Economic Zone Ltd. & 2 & No Such Survey \\
\hline Asian Paints Ltd. & 0 & No Such Survey \\
\hline Axis Bank Ltd. & 1 & Axis Cares \\
\hline Bajaj Auto Ltd. & 0 & No Such Survey \\
\hline Bajaj Finance Ltd. & 2 & ESAT Survey \\
\hline Bajaj Finserv Ltd. & 2 & ESAT Survey \\
\hline Bharat Petroleum Corporation Ltd. & 1 & No Such Survey \\
\hline Bharti Airtel Ltd. & 5 & Aon Hewitt \\
\hline Bharti Infratel Ltd. & 1 & No Such Survey \\
\hline Britannia Industries Ltd. & 1 & No Such Survey \\
\hline Cipla Ltd. & 9 & Survey \\
\hline Coal India Ltd. & 0 & No Such Survey \\
\hline Dr. Reddy's Laboratories Ltd. & 1 & No Such Survey \\
\hline Eicher Motors Ltd. & 0 & No Such Survey \\
\hline GAIL (India) Ltd. & 1 & No Such Survey \\
\hline Grasim Industries Ltd. & 1 & No Such Survey \\
\hline HCL Technologies Ltd. & 0 & No Such Survey \\
\hline HDFC Bank Ltd. & 0 & No Such Survey \\
\hline Hero MotoCorp Ltd. & 0 & No Such Survey \\
\hline Hindalco Industries Ltd. & 0 & No Such Survey \\
\hline Hindustan Unilever Ltd. & 1 & No Such Survey \\
\hline Housing Development Finance Corporation Ltd. & 0 & No such survey \\
\hline ICICI Bank Ltd. & 0 & No such survey \\
\hline ITC Ltd. & 3 & Survey \\
\hline Indiabulls Housing Finance Ltd. & 0 & No such Survey \\
\hline & & \\
\hline
\end{tabular}




\begin{tabular}{|c|c|c|}
\hline Indian Oil Corporation Ltd. & 7 & No Such Survey \\
\hline IndusInd Bank Ltd. & 0 & No Such Survey \\
\hline Infosys Ltd. & 3 & No Such Survey \\
\hline JSW Steel Ltd. & 3 & $\begin{array}{l}\text { Great place to work survey in } 2016 \text { - } \\
17\end{array}$ \\
\hline Kotak Mahindra Bank Ltd. & 2 & No Such Survey \\
\hline Larsen \& Toubro Ltd. & 0 & No Such Survey \\
\hline Mahindra \& Mahindra Ltd. & 2 & No Such Survey \\
\hline Maruti Suzuki India Ltd. & 2 & Annual Survey \\
\hline NTPC Ltd. & 1 & No Such Survey \\
\hline Oil \& Natural Gas Corporation Ltd. & 3 & $\begin{array}{l}\text { Employee Engagement \& Brand } \\
\text { Perception Survey "Anubandhan" }\end{array}$ \\
\hline Power Grid Corporation of India Ltd. & 0 & No Such Survey \\
\hline Reliance Industries Ltd. & 7 & R-Voice \\
\hline State Bank of India & 5 & Abhivyakti, NaiDisha \\
\hline Sun Pharmaceutical Industries Ltd. & 1 & No Such Survey \\
\hline Tata Consultancy Services Ltd. & 9 & Pulse Survey \\
\hline Tata Motors Ltd. & 0 & No Such Survey \\
\hline Tata Steel Ltd. & 0 & No Such Survey \\
\hline Tech Mahindra Ltd. & 0 & No Such Survey \\
\hline Titan Company Ltd. & 4 & No Such Survey \\
\hline UPL Ltd. & 3 & No Such Survey \\
\hline UltraTech Cement Ltd. & 1 & No Such Survey \\
\hline Vedanta Ltd. & 5 & No such survey \\
\hline Wipro Ltd. & 4 & Wipro on air podcast \\
\hline Yes Bank Ltd. & 3 & Yes club \\
\hline Zee Entertainment Enterprises Ltd. & 5 & No such survey \\
\hline
\end{tabular}

While assessing the result of the study (Table: 3), it is observed that the very word 'employee engagement' or 'employee satisfaction' had appeared as high as 9 times for the companies like Cipla and TCS. For Public Sector Undertaking like Indian Oil Corporation Limited, the count is 7 and for State Run bank SBI, it is 5. This outcome, along with the low mention of the term in earlier reports and a sustainable increasing trend, reflects a positive sentiment among companies to focus on employee engagement. The methodology and the processes of these companies for the assessment of Employee Engagement Index have been analyzed and it has been observed that the existing models have been used toevaluate it consist limited scope of coverage.

\subsection{Scope and limitations of research}

The research aimed at understanding, identifying and analyzing the prevailing models of employee engagement. Various relevant models have been thoroughly studied and the annual reports of all NIFTY 50 companies have been used as the basic data points. The usage of engagement / satisfaction terms has been counted to assess the focus of the companies in employee engagement. The models used to prepare the engagement questionnaire have been analyzed and a suitable model has been proposed. The key limitation of this research is the non-availability of other data points. The index is measured for most o the companies in last 2-3 years whereas the historical data is unavailable. The detailed methodology of the calculation is also not stated explicitly in many of the cases barring which performing the statistical analysis was not possible to correlate the index with profitability and operational efficiency.

\section{DISCUSSING AN ALL-ENCOMPASSING MODEL}

While contemplating on an all-inclusive questionnaire, this research work identifies the relevant broad areas which are to be considered to calculate the index. The questions like 'How', 'What', 'By whom', 'When', 'Why' and 'Which 
reinforcements' lead us to the desired outcome i.e. 'where does it lead to'. These six questions backed up by relevant theoretical models ensure the optimum coverage of all internal and external factors, motivation and hygiene

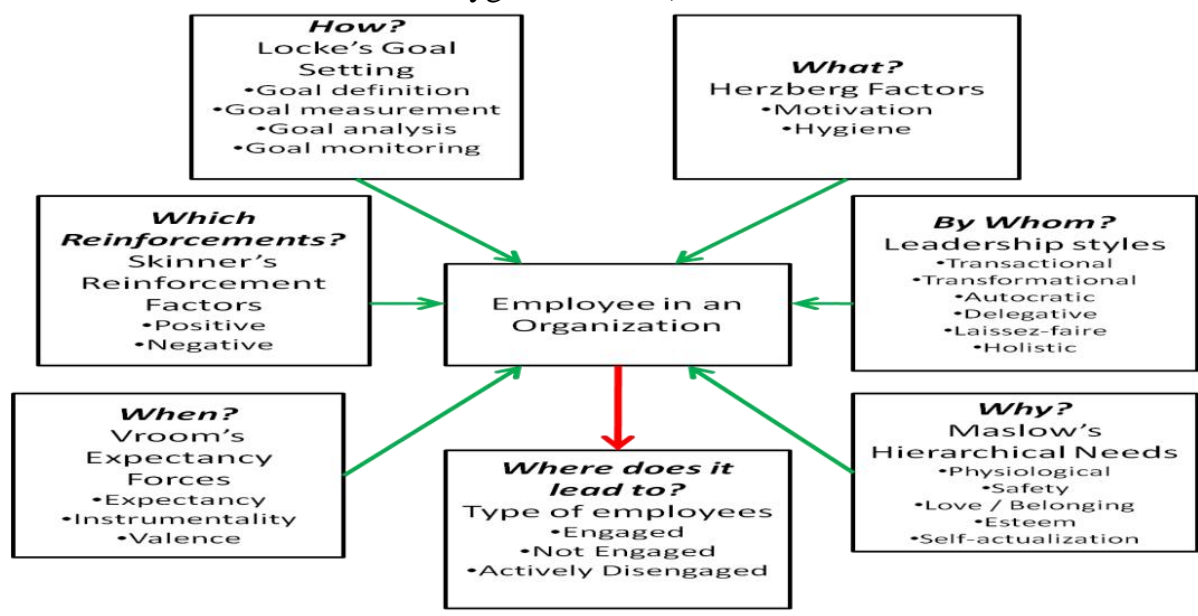

Fig:6: Seven Dimension Employee Engagement Model elements of inputs for the desired output and result in a suitable employee engagement model which we term as 'Seven Dimension Employee Engagement Model' (Figure: $6)$.

\section{REFERENCES}

\section{MODEL OUTCOME AND RECOMMENDATIONS}

The proposed model, as the name suggests, covers a wide range of input factors to enable an employee to righty figure out the answers / responses against a question posed against him to evaluate his engagement. The six steps / inputs of the organization to assess the seventh dimension are essentially require sample testing. We have performed the sample survey in Rau-Pithampur Industrial area of Indore, Madhya Pradesh, Mansarovar RIICO Industrial Area of Jaipur, Rajasthan and GIDC Industry area of Halol, Gujarat, India among approximately 250 employees at each of the places. It covered wide range of companies from Pharmaceutical, Automobile, Electrical equipment, FMCG and Services sector. The result outcome emphasizes the popularity of transactional and delegative leadership, positive reinforcement, motivation factors over hygiene factors, planned goal setting for higher employee engagement whereas the sample crowd was indecisive between the priority of esteem and safety needs. This sample study reinforces the fact that the proposed model and its placement to define the questionnaire has fared well amongst sample crowd. In continuation with this, sector specific outcome of the sample testing reinforced that 'one size fits all' approach does not hold good in this case. Employee engagement calculation and study require focused area at various levels of the proposed dimensions resulting in an encouraging and near-perfect result. This adds strength to both- the study and the recommended model.
[1] Maslach, C., Leiter, M .P. (1997), The truth about burnout. Jossey-Bass, San Francisco, CA.

[2] Maslach, C., Schaufeli, W.B., Leiter, M.P. (2001), "Job burnout”,Annual Revue Psychology,Vol. 52, pp.397-422.

[3] Schaufeli, W. B., Salanova, M., Gonza'lez-Roma', V., \& Bakker, A. B. (2002), "The measurement of engagement and burnout: A two sample confirmatory factor Analytic approach", Journal of Happiness Studies, 3, pp.71-92.

[4] Wellins, R., \&Concelman, J. (2005), "Creating a culture for engagement", Workforce Performance Solutions (www.WPSmag.com).

[5] Robinson, I. (2006), Human Resource Management in Organisations. London, CIPD.

[6] Gemma Robertson-Smith and Carl Markwick(2009), A report on Ëmployee Engagement A review of current Thinking, Institute for Employment Studies.

[7] Simpson, M.R. (2009) Engagement at Work: A Review of the Literature, International Journal of Nursing Studies, Vol. 46, pp.1012-1024.

[8] Susi, S., Jawaharrani,K. (2011) Work-Life Balance: The key driver of employee engagement, Asian Journal of Management Research,Vol -2-1, pp.474-483

[9] Agrawal, S. (2015), "Predictors of employee engagement: A public sector unit experience", Strategic HR Review, Vol.141-2, pp. 57-68.

[10] Agrawal, S., Ojha, R. P. (2016), "Employee engagement in new business horizon," (Article in Press). 